Service social

\title{
Répertoire de la condition masculine, Collectif Hommes et Gars sous la direction de Jean-Pierre Simoneau, Montréal, Éditions Saint-Martin, 1988,160 pages.
}

Jocelyn Lindsay

Volume 37, numéro 1-2, 1988

Par-delà les barrières des sexes

URI : https://id.erudit.org/iderudit/706407ar

DOI : https://doi.org/10.7202/706407ar

Aller au sommaire du numéro

Éditeur(s)

École de service social de l'Université Laval

ISSN

1708-1734 (numérique)

Découvrir la revue

Citer ce compte rendu

Lindsay, J. (1988). Compte rendu de [Répertoire de la condition masculine, Collectif Hommes et Gars sous la direction de Jean-Pierre Simoneau, Montréal, Éditions Saint-Martin, 1988,160 pages.] Service social, 37(1-2), 289-290.

https://doi.org/10.7202/706407ar d'utilisation que vous pouvez consulter en ligne.

https://apropos.erudit.org/fr/usagers/politique-dutilisation/ 
bution authentiquement québécoise à la constitution de ce champ. Ce livre a une portée auprès d'un vaste public; dans le contexte du travail social, nous croyons qu'il peut profiter à celles et ceux qui interviennent auprès des hommes et, notamment, aux intervenants... masculins.

Jocelyn LINDSAY

École de service social,

Université Laval.

Répertoire de la condition masculine, Collectif Hommes et Gars sous la direction de Jean-Pierre Simoneau, Montréal, Éditions Saint-Martin, 1988, 160 pages.

Comme l'indique Jean-Pierre Simoneau dans l'introduction, ce répertoire est d'abord issu du centre de documentation commencé en 1982 à l'intérieur du Collectif Hommes et Gars, organisme communautaire montréalais axé sur la condition masculine et offrant des services de différents types, allant de l'écoute téléphonique à la formation. Préoccupés de l'isolement dans lequel œuvrent plusieurs personnes intéressées par la condition masculine, les initiateurs de ce projet ont voulu développer un outil de référence qui favorise les échanges et le partage d'expériences, avec le souhait, à long terme, que se développe autour de cette thématique un réseau de support et d'entraide.

On trouve d'abord une liste de groupes, organismes et personnes ressources œuvrant en relation à la condition masculine; ceux-ci sont répertoriés selon le critère géographique (Montréal, Québec, Canada, États-Unis) ; sont aussi insérés leur adresse et un bref exposé de leurs sphères d'activités.

La seconde partie se compose essentiellement d'une "médiagraphie thématique" ; autrement dit, on regroupe une série d'ouvrages sous cinq volets : " être homme ", " paternité et famille ", " sexualité ", " santé et maladies-refuges ", et "violence". À l'intérieur de chacun d'eux, on trouve une présentation, une bibliographie, une filmographie française et anglaise et une discographie.

Évidemment, un tel ouvrage ne répond pas à toutes les questions; il est toutefois un instrument qui permet d'orienter la réflexion, d'effectuer un premier déblayage, de bien poser des questions plutôt que d'y répondre. Il faut aussi reconnaître que ce répertoire a été rendu possible grâce au bénévolat d'un ensemble de sympathisants.

Au plan de l'analyse du volume, nous estimons que les choix faits par les auteurs, à différents niveaux, auraient dû être davantage spécifiés. Pourquoi avoir choisi les cinq thématiques précitées et ne pas avoir inclus, par exemple, l'homme dans son rapport au monde du travail, ce qui est aussi une dimension importante au plan de la condition masculine? Pourquoi, dans la thématique "être homme ", ne pas avoir inclus des ouvrages ayant trait à la conscientisation à la condition masculine et à l'intervention ? Quels critères ont présidé au choix des différents ouvrages (livres, articles, films, disques) inclus dans la médiagraphie? 
Il faut remercier ce Collectif d'avoir réuni autant de matériaux disparates et de les avoir organisés d'une façon utile à la personne en quête d'informations sur la condition masculine.

Compte tenu de la nature des informations, aurait-il été mieux de présenter cet ouvrage dans un cahier à anneaux, qui permet les additions fréquentes, plutôt que dans un volume de type habituel? Qu'à cela ne tienne, les auteurs évoquent, à la page 112, la... prochaine édition du répertoire.

Jocelyn LINDSAY

École de service social,

Université Laval.

Les nouveaux visages de la pauvreté, par Madeleine GAUTHIER, (dir.), Québec, Institut québécois de recherche sur la culture, 1987, 258 pages.

Les nouveaux visages de la pauvreté, que vient de publier l'Institut québécois de recherche sur la culture, nous offre un recueil de textes présentant certaines facettes de la pauvreté au Québec. Treize collaborateurs ont participé à cette étude ; quelques-uns rattachés à l'Institut, mais la plupart venus de l'extérieur, dont plusieurs de l'Université Laval.

Le regroupement des textes sous quatre thématiques assure une certaine cohérence à l'étude. La première thématique, " Des situations ", traite du phénomène de la pauvreté à travers l'analyse de son incidence par rapport aux quatre catégories sociales vulnérables : les jeunes, les femmes, les personnes handicapées, les Indiens. La division suivante, "Des témoignages", regroupe quatre textes qui nous amènent à appréhender la pauvreté à travers des témoignages de jeunes, de réfugiés, de chambreurs et par le biais de certains récits québécois. La section "Des stratégies", nous éclaire sur des stratégies sociales de dépannage expérimentées au Québec, d'abord en milieu urbain, grâce à des associations volontaires d'assistance, et ensuite en milieu rural, grâce aux échanges informels qui se tissent pour faire face à la pauvreté. Les trois derniers textes sont à caractère plus théorique : un premier analyse les différentes approches de la mesure quantitative de la pauvreté ; les deux autres questionnent sa dynamique de développement.

Dans le contexte actuel d'une remise en cause de certains aspects de nos programmes de transfert, tels l'aide sociale et l'assurance-chômage, cette étude nous fournit matière à réflexion sur un certain nombre de carences de nos politiques sociales et économiques.

En particulier, l'article sur la pauvreté des femmes nous indique une croissance du phénomène depuis le début des années 1980, due en particulier à des problèmes et à des changements sociaux n'ayant pas été accompagnés des transformations institutionnelles conséquentes et qui nous auraient évité ce pas en arrière dans la lutte à la pauvreté. Il montre par exemple que le risque de la pauvreté est toujours plus élevé pour les femmes et cela, malgré la progression spectaculaire de leur participation au marché du travail. Ceci met en lumière le 